\title{
Komunikasi Krisis di Era New Media dan Social Media
}

\author{
Narayana Mahendra Prastya \\ Mahasiswa Pascasarjana Komunikasi \\ Universitas Gadjah Mada (UGM), Yogyakarta
}

\begin{abstract}
New media and social media have changed the practice of public relations. One area that changed is crisis communication. Because of these new technologies, crisis can be more complex. The pace of information, the uncertainty, and the rumours, are increasing. Public relations practitioners should include the new media and social media use in their crisis communication plan. Before doing that, public relations practitioners should change their mindset about social media and new media. The first part of this article contains introduction that describe the importance of communication in crisis management and the importance of social media and new media use in crisis communication. The second part is literature review, that consist of two themes: the concept about crisis communication; and crisis communication in the new media and social media era. The third part describes two cases from Indonesian corporation when they used social media and new media in crisis communication. Each cases explain the success story and the failed story in social media and new media use.
\end{abstract}

Keywords: crisis communication, new media, social media

\begin{abstract}
Abstrak
Media baru dan media sosial telah mengubah praktik Public Relations (PR). Salah satu area yang berubaha adalah aktivitas komunikasi krisis. Oleh karena teknologi baru ini, krisis bisa menjadi lebih kompleks. Arus informasi, ketidakjelasan, dan gosip, tengah meningkat. Para praktisi PR harus terlibat dalam pemanfaatan media baru dan sosial media dalam rencana komunikasi krisis mereka. Sebelum melakukan itu, praktisi PR harus mengubah cara pandang mereka terhadap media sosial dan media baru. Bagian pertama artikel ini berisi penjelasan mengenai pentingnya komunikasi dalam manajemen krisis dan pentingnya penggunaan media sosial dan media baru dalam komunikasi krisis. Bagian kedua mengulas literatur tentang konsep krisis komunikasi; dan komunikasi krisis di era media baru dan media sosial. Bagian ketiga membahas dua contoh kasus korporasi Indonesia yang sukses maupun gagal dalam menggunakan media sosial dan media baru dalam komunikasi krisis.
\end{abstract}

Kata Kunci: komunikasi krisis, media baru, media sosial 


\section{Pendahuluan}

Kehadiran new media dan social media telah mengubah cara para praktisi public relations (selanjutnya ditulis dengan $\mathrm{PR}$ ) dalam berpikir dan melaksanakan praktikpraktiknya. Dengan mengoptimalkan potensi yang dimiliki oleh social media maka praktik PR akan lebih mendunia, lebih strategis, semakin bersifat komunikasi dua arah dan interaktif, simetris atau dialogis dan lebih bertanggung jawab secara sosial. Hal ini cukup dapat mendasari bahwa pada era baru ini social media dapat dijadikan sebagai salah satu toolkit yang digunakan dalam strategi PR dalam berkomunikasi dengan publiknya (Grunig, 2009).

Salah satu praktik PR yang ikut berubah dengan berkembangnya teknologi komunikasi adalah komunikasi krisis. Perkembangan teknologi komunikasi memperbesar potensi akan hadirnya krisis akan semakin besar (Argenti, 2009). Pendapat lain mengungkapkan perkembangan teknologi dan informasi membuat orang-orang semakin peduli, semakin perhatian terhadap sebuah isu atau risiko yang dihadapi oleh organisasi.

Because of modern communication and information technologies, people are increasingly aware of the issues and risks associated with organizations and their industries. These technologies also afford a way of voicing concerns and of dialoguing on these issues
.... These risks and issues may form the bedrock for crises. (Cornelissen, 2011: 199)

Krisis yang muncul di era teknologi komunikasi yang baru - cyberspace misal ketika kita melihat ada tulisan di blog, website, mailing list, atau tulisan di Facebook berisi tuduhan terhadap seseorang, organisasi, kualitas sebuah produk atau layanan. Padahal tuduhan tersebut belum bisa dipastikan kebenarannya (Millar dan Heath, 2004). Rumor merupakan bentuk spesial untuk sebuah krisis - bahkan di cyberspace saat ini sifatnya sudah lebih provokatif. Weiner (seperti dikutip Holmes, 2011: 4) menggambarkan krisis yang terjadi di era media baru sebagai berikut:

Before the company knows about the incident, cameras are on the scene. In the absence of real information, organization cannot respond meaningfully. However that doesn't stop the media from reporting on it live, minute by minute

Dasar dari komunikasi krisis adalah memberikan respon dengan segera begitu krisis terjadi, dengan pesan yang terbuka dan jujur kepada para pemangku kepentingan (stakeholder) baik itu yang terpengaruh secara langsung atau tidak langsung. Perusahaan atau organisasi punya waktu "minimal 40 menit hingga maksimal 12 jam" untuk memberikan penjelasan versi mereka atas sebuah krisis. Jika dalam rentang waktu tersebut 
organisasi atau korporasi gagal merilis informasi yang relevan, maka kepercayaan publik kemungkinan sudah turun terhadap informasi yang akan dirilis di luar time frame tadi (Pinsdorf seperti dikutip Tan, 2006).

Rentang waktu tadi menjadi semakin singkat di era media baru, di mana informasi beredar begitu intens dan begitu cepat. Tentu saja ini menuntut PR harus merespon dengan cepat situasi krisis yang terjadi. Di sinilah komunikasi krisis berperan. Werner (1990, dalam Millar \& Heath, 2004) berpendapat bahwa ketika krisis mulai meningkat, hal yang paling penting untuk dilakukan adalah komunikasi. Pendapat lain dari Coombs (dikutip dari Kyhn, 2008) mengungkapkan bahwa krisis komunikasi merupakan "darah kehidupan" bagi seluruh aktivitas manajemen krisis dan memainkan peran penting di manajemen krisis.

Komunikator dalam krisis di era media baru harus bertarung di dalam siklus informasi yang berlangsung selama 24 jam. Sebuah tindakan yang cepat dan efektif harus dilakukan oleh perusahaan ketika menghadapi apapun problem yang dihadapi. Segera memberikan pesanyang akan disampaikan, sebab membiarkan rumor beredar secara liar hanya akan menambah kesulitan bagi organisasi (Millar \& Heath, 2004). Kalah cepat dan juga kalah sigap dalam merespon konten media sosial, utamanya yang bernada negatif, akan membawa organisasi mengalami kerugian dalam situasi krisis (Landau, 2011).

Seperti sudah dipaparkan sebelumnya, kecepatan menjadi sesuatu yang harus dipertimbangkan oleh korporasi atau organisasi saat berkomunikasi di saat krisis. Adalah tantangan bagi komunikator di era krisis untuk berkomunikasi dengan segera menanggapi segala kabar yang ada termasuk menjawab isu, rumor, selentingan, kabar burung, dan hal-hal lain yang bisa merusak citra perusahaan namun di sisi lain informasi atau data yang dimiliki masih belum cukup.

Tulisan ini akan memberikan beberapa contoh bagaimana perusahaan atau organisasi memanfaatkan media sosial mereka dalam sebuah krisis. Di bagian akhir, penulis akan memberikan rekomendasi bahwa dalam perencanaan manajemen krisis, perusahaan atau organisasi harus memasukkan penggunaan media sosial. Pasalnya, perencanaan merupakan awal dari suksesnya sebuah kegiatan kehumasan termasuk di dalamnya komunikasi krisis (Hardjana, 1998; Cutlip, et.al, 2005; Landau, 2011).

\section{Konsep-Konsep dalam Komunikasi Krisis}

Komunikasi krisis merupakan salah satu peran PR. Pada umumnya krisis diterjemahkan sebagai sesuatu yang datang secara mengejutkan serta 
menghadirkan ancaman bagi organisasi, perusahaan, atau industri, begitu juga terhadap publik mereka, produk, layanan, ataupun nama baik yang sudah dimiliki. Sebagai ancaman, maka krisis harus ditangani secara cepat agar organisasi dapat berjalan normal kembali. Krisis menempatkan penampilan perusahaan berada dalam penilaian publik. Publik biasanya membutuhkan respon yang segera dari organisasi (Putra, 1999).

Ada tiga kondisi yang umum terjadi dalam krisis. Menurut Argenti (2009: 259), hal tersebut adalah: (1) elemen-elemen yang sifatnya tak terduga; (2) informasi yang tidak mencukupi; dan (3) begitu cepatnya dinamika yang terjadi. Sementara Millar \& Heath (2004) berpendapat bahwa dalam situasi krisis berita bisa menyebar begitu cepat yang berpotensi melumpuhkan jajaran manajemen sebelum mereka bisa mengontrol situasi dengan efektif. Untuk menjaga citra positif, sebuah korporasi harus menciptakan langkah yang cepat dan efektif saat menghadapi problem apapun, sebab krisis bisa merusak citra paling positif dari sebuah organisasi yang sudah mapan sekalipun.

\section{Sedangkan Hardjana} berpandangan dalam situasi krisis terjadi peningkatan arus informasi yang luar biasa, sistem komunikasi kehilangan keseimbangan, kandungan emosi dalam komunikasi krisis sangat mencolok, jaringan antara komunikasi antar pribadi dan komunikasi media, serta yang terakhir keterikatan manusia pada media massa mengalami lonjakan besar. Dalam era media baru dan media sosial, keterikatan manusia tidak hanya sebatas pada media massa, tetapi juga pada jejaring sosial. Jaringan komunikasi antarpribadi juga akan meningkat melalui jejaring-jejaring sosial tersebut.

Ada tiga prinsip utama dalam komunikasi krisis, yakni: menyampaikan pesan dengan cepat atau segera menyampaikan pesan, konsisten, dan terbuka (Coombs, 2006). Menyampaikan pesan dengan cepat berarti memberikan kesempatan bagi pemangku kepentingan, terutama media massa, untuk mengetahui tentang apa yang sebenarnya terjadi. Tujuannya adalah mengisi kekosongan informasi ketika krisis berlangsung. Respon yang lambat justru memberikan kesempatan bagi pihak lain - terutama yang ingin menghancurkan reputasi organisasi atau perusahaan tersebut untuk mengisi kekosongan informasi tersebut dengan spekulasi atau informasi yang salah. Respon yang cepat juga akan membentuk persepsi di mata publik bahwa perusahaan atau organisasi tersebut dapat mengendalikan situasi. Akan tetapi, respon yang bersifat segera ini juga memiliki kelemahan. Coombs (dalam Soule, 2010) mengatakan kerugian utama dari respon cepat adalah tentu saja kecepatan meninngkatkan tingkat risiko yang dihadapi.

Prinsip kedua yakni konsisten, maksudnya adalah berbagai pesan yang 
disampaikan organisasi bebas dari kontradiksi. Dengan kata lain, konsistensi merupakan berbicara dalam satu suara. Memang tidak mungkin dalam situasi krisis hanya satu orang saja yang berbicara untuk mewakili perusahaan atau organisasi. Bagaimanapun, tim komunikasi krisis harus memastikan bahwa juru bicara yang berbeda akan memberikan pesan yang konsisten.

Prinsip ketiga adalah keterbukaan. Menurut Coombs, prinsip ini merupakan satu-satunya prinsip yang kontroversial. Kontroversi muncul akibat interpretasi yang berbeda terhadap pemahaman keterbukaan ini. Interpretasi pertama adalah keterbukaan berarti orang-orang dalam organisasi (yang berwenang untuk memberikan pernyataan) selalu siap dan bersedia untuk berkomunikasi dengan para pemangku kepentingan, terutama media massa. Keengganan untuk berkomunikasi dengan pemangku kepentingan akan menimbulkan kesan bahwa organisasi tersebut sangat tertutup, berusaha menyembunyikan sesuatu, atau tidak mampu menangani krisis.

Interpretasi kedua mengenai keterbukaan adalah pengungkapan secara terbuka sepenuhnya (full disclosure), yakni organisasi harus mengatakan semua yang mereka ketahui tentang krisis segera setelah mereka mendapatkan informasi. Kepentingan hukum terkadang merekomendasikan keterbukaan secara terbatas (limited disclosure) karena pengungkapan secara terbuka sepenuhnya dapat membawa organisasi ke masalah hukum dan kerugian finansial. Organisasi sebaiknya menyeimbangkan perhatian mereka terhadap pemangku kepentingan finansial (misal pemegang saham atau pemberi pinjaman) dengan perhatian kepada pemangku kepentingan yang mengalami kerugian akibat krisis (misal anggota komunitas, pelanggan, atau karyawan).

Pentingnya komunikasi krisis sebagai bagian dalam krisis manajemen diungkapkan oleh sejumlah ahli. Coombs (seperti dikutip Kyhn, 2008) menyatakan bahwa komunikasi krisis adalah "darah kehidupan" dari seluruh kegiatan manajemen krisis dan memainkan peran vital di setiap tahap dari manajemen krisis. Pendapat lain yakni dari dari Fearn-Banks (seperti dikutip Kyhn, 2008) menjelaskan dalam manajemen krisis yang efektif terdapat komunikasi krisis yang tidak hanya mengurangi atau menghilangkan krisis, tetapi juga sedikit banyak dapat menghadirkan reputasi bagi organisasi yang lebih baik dibanding sebelum terjadinya krisis.

Ketika intensitas krisis mulai meningkat, tugas terpenting adalah, tentu saja, fase komunikasi - menyampaikan pesan dari perusahaan dengan lengkap, terorganisasi, dan rapi. Jika ditangani dengan baik, komunikasi bisa mengurangi kemungkinan meluasnya masalah dan mempersempit potensi gangguan yang bisa merusak perusahaan. 
Deliver the crisis response message: Get your message out quickly. According to the literature, giving the who, what, how, when, why, and where as quickly as possible is crucial to a company's crisis management objectives. Letting the story dribble out only prolongs the agony, and results in new and potentially damaging headlines with each dose of new information (Millar dan Heath, 2004: 129)

Dalam bentuknya yang paling maju, PR merupakan bagian dari pemecahan masalah dan proses perubahan organisasi, yang dikelola menurut ilmu pengetahuan. Praktisi humas jenis ini memakai teori danbukti terbaik yang ada dalam empat proses pemecahan masalah yakni mendefinisikan masalah, (2) membuat rencana dan program, (3) bertindak dan berkomunikasi, serta (4) mengevaluasi program. Setiap langkah sama pentingnya tetapi proses dimulai dengan pengerahan keerdsan untuk mendiagnosa masalah. Informasi dan pemahaman yang dikembangkan pada langkah pertama memotivasi dan mengarahkan langkah selanjutnya dalam proses. Tentu saja dalam kenyataannya diagnosa, perencanaan, perlaksanaan, dan evaluasi tidak dapat dibagi dengan sangat rapi, karena proses bersifat berkesinambungan dan berputar, serta diterapkan dalam keadaan dinamis (Cutlip, dkk, 2005).

Seperti halnya kegiatan humas yang lainnya, perencanaan merupakan faktor penting bagi krisis komunikasi. Menurut Ferguson (1999: 100): "crisis communication plan is key to survival of an organization - knowing what to say, when, and to whom". Rencana komunikasi menyangkut elemen seperti indikator krisis, tim komunikasi, strategi komunikasi, respon, mekanisme kontrol, evaluasi, dan lampiran yang berisi format dan panduan dari aktivitas komunikasi seperti merilis siaran pers dan pencatatan aktivitas harian. Perencanaan komunikasi krisis selain dapat menyelamatkan organisasi dari kejutan-kejutan yang melumpuhkan sistem komunikasi keorganisasian, juga dapat memperkokoh bantuan kelompok pendukung strategis, sehingga tidak terjadi krisis kepercayaan yang membuat penanganan krisis menjadi suatu kemustahilan (Hardjana, 1998).

Akan tetapi, sejumlah ahli (seperti dikutip Kyhn, 2008) menilai perencanaan belum tentu bisa menangani semua krisis, dan saat ini, perusahaan harus langsung merespon kepada krisis. Komunikasi perlu dilakukan sedini mungkin sebelum muncul kecurigaan masyarakat. Singkatnya, masyarakat memperoleh informasi yang lengkap dan tahap demi tahap tentang langkah yang diambil perusahaan sebagai solusi krisis (Hardjana, 1998). 


\section{Komunikasi Krisis di Era Media Baru dan Media Sosial}

Penggunaan internet terutama pada masa krisis komunikasi dapat mengidentifikasi masalah dengan manajemen untuk kemudian dikomunikasikan kepada publik. Dunia PR memasuki masa keemasan karena teknologi internet telah membawa praktisi PR mampu mencapai publik sasaran secara langsung tanpa intervensi dari pihak-pihak lain seperti wartawan atau redaksi media massa yang biasaanya bertindak sebagai penjaga gawang dan melakukan penyensoran terhadap informasi kepada publik. Namun begitu kebanyakan aktivitas PR dalam internet masih sebatas penggunaan media satu arah, dari atas ke bawah. Untuk penerbitan informasi masih menggunakan pola komunikasi massa yang tradisional (Ardianto, dkk., 2007).

Penelitian yang pernah dilakukan terkait komunikasi krisis di era media baru, misalkan: Difussion of Traditional and New Media Tactis in Crisis Communication (Taylor \& Perry, 2005), Fighting Social Media Wildfire: How Crisis Communication Must Adapt to Prevent from Fanning The Flames (Soule, 2010), dan How Social Media is Changing Crisis Communication: A Historical Analysis (Landau, 2011)

Penelitian-penelitian tersebut menyimpulkan bahwa media sosial saat ini sudah menjadi bagian integral dari perilaku komunikasi dan organisasi tidak bisa mengabaikan penggunaan media sosial dalam komunikasinya, sebab media sosial memiliki potensi untuk menyebarkan sebuah kabar - mulai dari keluhan hingga sebuah rumor atau memang bertujuan menjatuhkan kredibilitas - dengan kecepatan luar biasa. Namun begitu banyak faktor yang membuat bahwa internet dan juga media sosial masih belum diintegrasikan dalam krisis komunikasi. Alasan-alasan tersebut misalkan terbentur masalah peraturan, keterbatasan teknologi, hingga kurangnya kemampuan Divisi Public Relations dalam pengembangan website. Namun begitu, dalam beberapa tahun ke depan, ketika organisasi memutuskan untuk tidak merespon krisis melalui piranti internet, maka hal tersebut bisa diartikan oleh publik atau oleh media sebagai sikap "no comment".

Organisasi bisa menggunakan media sosial untuk membangun hubungan dengan publik, dan menyediakan berbagai informasi terkait organisasi dan layanan yang diberikan organisasi kepada publik yang berbeda-beda, baik itu publik secara langsung atau tidak langsung. Sementara itu website memungkinkan organisasi untuk berkomunikasi dengan media secara lebih efektif dan efisien dan menjadi sarana untuk mengklarifikasi informasi yang salah (McLennan \& Howell, 2011).

Penelitian lain terkait krisis di era media sosial dilakukan Wigley dan Zhang 
(2011). Hasil penelitian ini menujukan bahwa hampir 48\% dari responden menyatakan bahwa mereka menggunakan social media dalam strategi manajemen krisis yang dilakukan. Aplikasi yang paling sering digunakan adalah micro-blogging Twitter yang difokuskan untuk tujuan distribusi informasi. Penelitian ini menunjukkan bahwa praktisi PR yang menggunakan social media dalam strategi manajemen krisisnya maka mereka memiliki keyakinan yang lebih besar bahwa organisasi mereka dapat mengatasi krisis dengan lebih baik. Hasil penelitian ini juga menekankan pada pihak manajemen organisasi agar dari saat ini mulai menggunakan social media ke dalam strategi manejemen krisis yang mereka terapkan. Praktisi yang cerdas mengetahui bahwa social media dapat membantu persiapan pada organisasi dari segala sudut pandang ketika terjadi halhal yang tak diinginkan. Praktisi dapat memonitor isu yang berkembang di masyarakat seputar organisasi melalui social media.

$$
\text { Wigley dan Zhang (2011) }
$$
mengambil contoh kasus krisis yang dialami oleh British Petroleum ketika terjadi ledakan di salah satu kilang minyak lepas pantai yang menyebabkan sebelas orang tewas dan 17 lainnya terluka. Selain itu dampak lingkungan dari terjadinya ledakan itu adalah tercemarnya air laut tersebut dengan minyak mentah yang bersumber dari kilang tersebut dan oleh karena itu beberapa bulan kemudian izin operasional perusahaan minyak inipun dicabut.

Puncak krisis terjadi ketika British Petroleum masih menghindar untuk menyatakan bahwa ini bukan merupakan kelalaian mereka dan terus mengambinghitamkan pihak-pihak lain yang berkaitan serta komentar salah satu petinggi manajemen yang mengatakan bahwa tumpahan minyak tersebut tidak perlu dibesar-besarkan karena dibandinng dengan luasnya lautan tersebut jumlah minyak tersebut hanyalah sebagian kecil saja. Beruntungnya adalah British Petroleum memiliki berbagai akun perusahaan di beberapa social media yang seharusnya dapat membuka peluang untuk dapat meredam krisis. Namun kenyataan berkata lain, British Petroleum gagal dalam memanfaatkan peluang emas ini.

Selama krisis terjadi, mereka terus berusaha untuk meng-update informasi terbaru mengenai perkembang ledakan di kilang minyak tersebut serta melakukan konfirmasi perihal kejadian tersebut dan usaha dalam melakukan pembersihan minyak yang mencemari tersebut. Namun sayang hal ini menjadi sesuatu yang tidak maksimal ketika followers dari berbagai social media yang mereka miliki ini jauh lebih kecil dibanding dengan mereka yang kontra terhadap perusahaan minyak ini. Sebut saja dalam hal ini terdapat sekitar 6.472 video yang mengandung atas kecaman dan protes social terhadap British Petroleum. Sama halnya dengan 
followers Twitter akun perusahaan hanya berjumlah sekitar 18.596 yang sangat kecil bila dibandingkan dengan followers akun yang kontra terhadap British Petroleum yang berjumlah sekitar 190.561.

Hal ini menjadi sulit bagi British Petroleum dalam memanfaatkan akun social media yang dimiliki untuk mengatasi opini yang berkembang di luar sana. Jumlah followers yang terlampau jauh lebih kecil menyebabkan update informasi yang dilakukan secara intens menjadi tidak terdengar atau terekspos secara massal. Hal ini juga yang dapat dijadikan koreksi bersama, seandainya British Petroleum lebih intens lagi dalam menjalin hubungan dengan lebih banyak followers dan memiliki kualitas hubungan yang baik, mereka akan memberikan dukungan mereka dengan me-retweet seputar info perbaikan atau penanganan limbah di laut dan konfirmasi perihal kejadian ledakan tersebut.

Salah satu cara ini merupakan cerminan bagaimana followers sudah berperan aktif menjadi "pembela" perusahaan dan juga mendukung usaha perusahaan untuk meredam isu yang berhembus. Kesalahan lain yang dilakukan oleh British Petroleum adalah pihak perusahaan hanya berupaya untuk meng-update informasi namun tidak berupaya untuk merespon komentarkomentar negatif yang diterima sehingga kesannya mereka seperti mengabaikan opini dari publik. Padahal dengan merespon komentar-komentar tersebut praktisi bisa menggunakan sebagai alat evaluasi sejauh mana pemahaman publik terhadap update informasi yang diberikan dan sejauh mana isu ini telah berkembang. Selain itu pihak perusahaan juga bisa menampung kritikan yang datang guna sebagai bahan pertimbangan untuk melakukan pertanggungjawaban dan langkah perbaikan perusahaan pada tahap selanjutnya.

\section{Contoh Kasus Indonesia: Kesuksesan dan Kegagalan dalam Komunikasi Krisis}

Di bagian ini akan dipaparkan dua contoh kasus penggunaan media baru dan media sosial oleh perusahaan di Indonesia. Pertama, adalah contoh sukses dari penggunaan media sosial yang ditunjukkan oleh maskapai penerbangan Garuda Indonesia. Garuda berhasil memberikan respon dengan cepat dan bertindak secara konsisten.

Kedua, adalah contoh kegagalan memanfaatkan media baru oleh PT Liga Prima Indonesia ketika mereka menanggapi rumor bahwa kompetisi Liga Primer Indonesia berhenti/dihentikan. PT Liga Prima Indonesia tidak memberikan respon dengan cepat dan tidak bertindak secara konsisten. 
Kesuksesan Pemanfaatan Media Sosial dan Media Baru dalam Krisis: Garuda Indonesia dalam Kasus Pemogokan Pilot, Juli 2011

Maskapai penerbangan Garuda Indonesia menghadapi ancaman mogok pilot pada akhir Juli 2011. Mereka mengaku tidak puas dengan pembayaran gaji yang timpang antara pilot lokal dengan pilot asing. Sedikitnya ada 200 orang pilot yang melakukan pemogokan. Mereka tergabung dalam Asosiasi Pilot Garuda (APG). Pemogokan itu hanya berlangsung satu hari, atau berakhir lebih cepat dari ancaman APG sebelumnya ("Garuda Indonesia Pilot Strike Ends Early, Few Delays”, Reuters Online, 28 Juli 2011).

Selama terjadi pemogokan, Garuda secara intensif menjalin komunikasi dengan para penumpang atau calon penumpang melalui akun Twitter (@IndonesiaGaruda). Ada tiga kali "kicauan" yang disampaikan oleh Garuda Indonesia dan seluruhnya dalam bahasa Inggris (lihat tabel 1):

Tabel 1. Penjelasan Garuda Indonesia berkaitan dengan pemogokan pilot

\begin{tabular}{lll}
\hline No & \multicolumn{1}{c}{ Isi Pesan } & \multicolumn{1}{c}{ URL } \\
\hline 1 & @IndonesiaGaruda PT. Garuda Indonesia & http://twitter.com/\#!/Indonesia \\
& (1/3) Garuda Indonesia would like to & Garuda/status/96119842486226 \\
address our passengers concerns over the & 944, diakses 5 November 2011 \\
possible 1-day strike by some pilots on & \\
Thursday, 28/o7/11 & \\
27 Jul via web & \\
@IndonesiaGaruda PT. Garuda Indonesia & http://twitter.com/\#!/Indonesia \\
& $\begin{array}{l}\text { (2/3) Pse be assured GA Management } \\
\text { takes all necessary steps\&actions to }\end{array}$ & Garuda/status/96120686543769 \\
ensure that all domstic\&intl flight will & \\
operate normally on the day & \\
27 Jul via web & \\
@IndonesiaGaruda PT. Garuda Indonesia & http://twitter.com/\#!/Indonesia \\
(3/3) Customer satisfaction is the focus of & Garuda/status/96121044020113 \\
everything we do at Garuda Indonesia, & 408, diakses 5 November 2011 \\
and we appreciate your continued support & \\
\& understanding. & \\
27 Jul via web
\end{tabular}


Garuda Indonesia juga melakukan komunikasi dengan opinion leader yakni Fadjroel Rahman, seorang mantan aktivis yang juga merupakan pemimpin media massa Pedomannews.com. Ada empat "kicauan" Garuda untuk Fadjroel yang semua berisi penjelasan Garuda tentang situasi yang terjadi (lihat tabel 2):

Tabel 2. Komunikasi Garuda Indonesia dengan opinion leader

\begin{tabular}{|c|c|c|}
\hline No & Isi Pesan & URL \\
\hline \multirow[t]{3}{*}{1} & @IndonesiaGaruda PT. Garuda Indonesia & \multirow{3}{*}{$\begin{array}{l}\text { http://twitter.com/\#!/Indone } \\
\text { siaGaruda/status/9508271022 } \\
5268736 \text {, diakses } 5 \text { November } \\
2011\end{array}$} \\
\hline & $\begin{array}{l}@ \text { fadjroel @PedomanNEWScom kontrak } \\
\text { pilot asing adlh smntra mnunggu kadet yg } \\
\text { slsai pendidkan. Hanya setahun. Tdk ada } \\
\text { kbjakan yg mengancam }\end{array}$ & \\
\hline & 24 Jul via Twitter for BlackBerry® & \\
\hline \multirow[t]{3}{*}{2} & $@$ IndonesiaGaruda PT. Garuda Indonesia & \multirow{3}{*}{$\begin{array}{l}\text { http://twitter.com/\#!/Indones } \\
\text { iaGaruda/status/95083140510 } \\
\text { 523392, diakses } 5 \text { November } \\
2011\end{array}$} \\
\hline & $\begin{array}{l}@ \text { fadjroel @PedomanNEWScom mngmnt } \\
\text { membuka pintu utk dialog lbh lanjut. Kontrk } \\
\text { pilot asing adlh brsft sementara (bridging) } \\
\text { slama setahun. }\end{array}$ & \\
\hline & 24 Jul via Twitter for BlackBerry® & \\
\hline \multirow[t]{3}{*}{3} & @IndonesiaGaruda PT. Garuda Indonesia & $\begin{array}{l}\text { http://twitter.com/\#!/Indone } \\
\text { siaGaruda/status/950840869 }\end{array}$ \\
\hline & $\begin{array}{l}\text { @fadjroel @PedomanNEWScom pilot kantrk } \\
\text { tdk mnrma faslts lain yg ditrma plot ttp. } \\
\text { Aturan GA sesuai stndar safety aturan IOSA } \\
\text { (IATA), ICAO dll }\end{array}$ & $\begin{array}{l}\text { siaGaruda/status/950840869 } \\
84577024, \quad \text { diakses } \\
\text { November } 2011\end{array}$ \\
\hline & 24 Jul via Twitter for BlackBerry® & \\
\hline \multirow[t]{3}{*}{4} & @IndonesiaGaruda PT. Garuda Indonesia & $\begin{array}{l}\text { http://twitter.com/\#!/Indone } \\
\text { siaGaruda/status/950855525 }\end{array}$ \\
\hline & $\begin{array}{l}\text { @fadjroel @PedomanNEWScom recruit pilt } \\
\text { asing th disetujui APG. Dilkukan utk } \\
\text { menopang perkembangan GA. Murni alsn } \\
\text { bisnis. } 2012 \text { nil plt asng }\end{array}$ & \multirow[t]{2}{*}{$\begin{array}{l}\text { O3762944, diakses } \\
\text { November } 2011\end{array}$} \\
\hline & 24 Jul via Twitter for BlackBerry® & \\
\hline
\end{tabular}


Akun Twitter@IndonesiaGaruda juga beberapa kali me-retweet beritaberita dari media massa online. Berita yang di-retweet adalah berita yang menguntungkan posisi Garuda (lihat tabel 3):

Tabel 3. Daftar berita

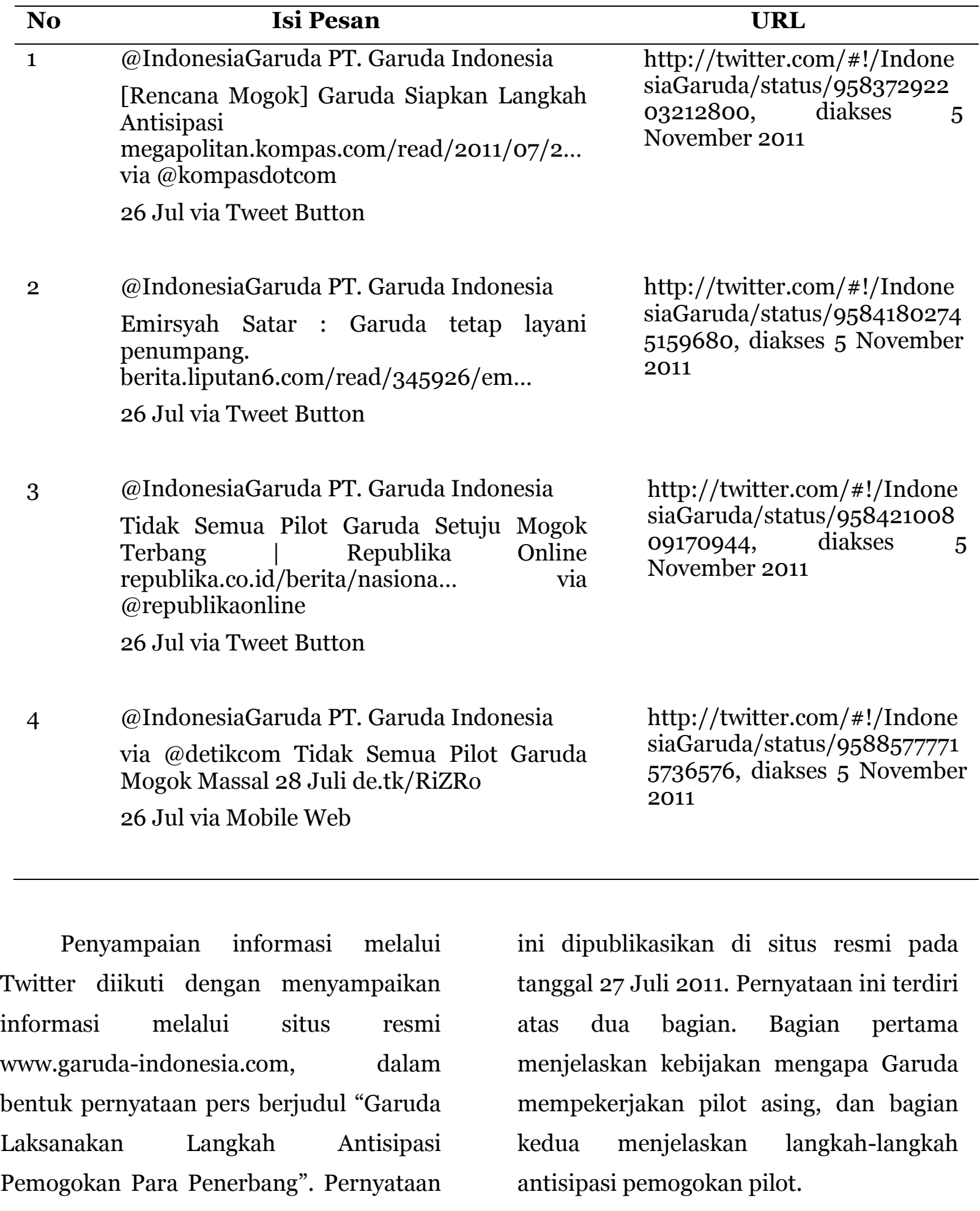


Di bagian pertama, Garuda melakukan strategi "menyerang" pihak lain yakni pilot yang melakukan pemogokan. Garuda menyebut pilot yang mogok tersebut bersikap tidak kooperatif dalam perundingan karena mengajukan tuntutan yang memberatkan manajemen. Selain itu motif pemogokan juga disebutkan tidak masuk akal.

Selain itu Garuda menyatakan bahwa alasan pemogokan tersebut adalah hal yang aneh. Garuda mulai merekrut para penerbang asing sejak bulan Oktober 2010 dan telah melaksanakan sosialisasi tersebut kepada karyawan, khusus para penerbang, sejak bulan Januari 2011 lalu. Dengan demikian menjadi hal yang agak aneh apabila penggunaan pilot kontrak termasuk pilot asing menjadi/baru dipermasalahkan pada saat ini.

Namun demikian sebelum pertemuan berlangsung/berlanjut, pihak APG (Asosiasi Pilot Garudapen) meminta agar jajaran operasi (dalam hal ini Direktur Operasi Garuda Capt. Ari Sapari dan VP Flight Operation Capt. Samad yang hadir dalam pertemuan tersebut) untuk tidak mengikuti pertemuan.

Hal tersebut tidak dapat diterima oleh manajemen mengingat Capt. Ari Sapari selaku Direktur Operasi dan Capt.Samad selaku VP.Flight Operation secara kedinasan merupakan "lembaga" yang bertanggungjawab atas kegiatan operasional penerbangan Garuda termasuk para penerbang Garuda.
Bagian kedua memberikan penjelasan langkah-langkah antisipasi Garuda terkait aksi pemogokan ini. Bagian kedua berisi penjelasan Garuda tentang layanan mereka selama pemogokan. Garuda menyatakan telah menyiapkan para penerbang yang selama ini bertugas sebagai instruktur dan para penerbang yang menduduki jabatan struktural dalam manajemen perusahaan untuk melaksanakan penerbangan pada 28 Juli. Garuda telah menyiapkan akomodasi bagi para penerbang di hotel-hotel terdekat area bandara Soekarno-Hatta untuk "standby", apabila sewaktu-waktu diperlukan untuk menerbangkan pesawat.

Pemanfaatan media sosial dan media baru oleh Garuda Indonesia dalam krisis sudah cukup baik. Garuda memanfaatkan Twitter untuk segera menyampaikan informasi. Informasi tersebut juga konsisten dengan yang disampaikan dalam pernyataan di situs resmi. Ketika informasi sudah disampaikan dengan segera, para penumpang atau calon penumpang tidak akan kebingungan dan dapat mengambil keputusan. 
Kegagalan Pemanfaatan Media Sosial dan Media Baru dalam Krisis: PT Liga Prima Indonesia dalam Mengklarifikasi Masa Depan Kompetisi LPI

Contoh kedua adalah komunikasi krisis yang dilakukan PT Liga Prima Indonesia, yang merupakan operator dari kompetisi Liga Prima Indonesia (LPI). Kompetisi ini mulai bergulir pada 8 Januari 2011 dan berakhir pada penghujung Mei 2011. Kompetisi ini tidak diakui oleh Persatuan Sepakobla Seluruh Indonesia (PSSI) yang kala itu diketuai Nurdin Halid. Sementara federasi sepakbola dunia (FIFA) menyebut LPI sebagai breakaway league atau liga yang memisahkan diri.

Sejak awal terbentuknya, banyak resistensi dan sikap skeptis terhadap LPI. Kompetisi yang mengklaim profesional karena tak menggunakan dana APBD dalam operasional klub-nya ini juga tak mendapatkan sambutan yang positif dari masyarakat. Stadion sepi penonton adalah pemandangan yang umum terjadi di LPI.

Dalam berkomuikasi dengan publik, LPI menggunakan situs resmi (www.ligaprima.co.id) dan akun Twitter (@ligaprima). Selain itu juru bicara LPI, Abi Hasantoso, juga sering menyampaikan informasi melalui akun Twitter pribadinya (@thereal_abi_lpi).

Krisis terjadi ketika LPI ketika putaran pertama berakhir, penghujung Mei 2011. Media massa memberitakan bahwa kompetisi ini tidak akan dilanjutkan. Media massa melansir komentar dari sejumlah pelatih atau pengurus dari klub-klub papan atas kontestan LPI, bahkan dari para pengurus LPI sendiri yang memang mengindikasikan bahwa kompetisi sudah berakhir (misalkan: "Dikabarkan Berhenti, LPI Belum Merespon", www.beritajatim.com, 21 Juni 2011, oo:15WIB; "Tak Ada Lagi Putaran Kedua, LPI Selesai?", www.okezone.com, 30 Mei 2011, 09:06 WIB; "Putaran Kedua LPI Tidak Dilanjutkan," www.metrotvnews.com, 17 Juni 2011, 09:06 WIB).

Pada jadwal yang telah disusun, LPI mengagendakan putran kedua dimulai 12 Juni. Tetapi mendekati hari tersebut tidak ada tanda-tanda kompetisi bakal berlanjut. Bahkan keterangan pertama bahwa kompetisi putaran kedua baru bergulir lagi di bulan September didapatkan media massa dari pernyataan para pengurus klub kontestan. Selama isu tersebut bergulir, LPI melalui akun Twitter-nya memberikan pernyataan yang bersifat normatif misalkan "menunggu keputusan resmi" atau "admin tidak memiliki kewenangan untuk menjawab”. Pihak LPI baru memberikan keterangan resmi mengenai kepastian waktu kapan putaran kedua mulai bergulir, pada hari Jumat 10 Juni 2011, sore WIB. Melalui keterangan pers yang dikirimkan ke redaksi media massa melalui surat 
elektronik, LPI menerangkan putaran kedua berlangsung pada 17 September.

Namun jeda kompetisi paruh musim yang teramat panjang - sekitar tiga bulan - kembali memunculkan rumor bahwa putaran kedua LPI tidak akan bergulir dan kompetisi ini sudah berakhir. Menghadapi rumor seperti ini, pihak LPI masih bertahan dengan jawaban yang normatif kepada publik.

Pada akhirnya LPI bertindak dengan mengeluarkan pernyataan resmi bahwa putaran kedua ditunda hingga batas waktu yang belum bisa ditentukan. Pengumuman itu disampaikan pada hari Rabu (27 Juli 2011) sore WIB melalui situs resmi mereka dan selanjutnya pengumuman tersebut dilansir oleh sejumlah media massa (misal baca: "LPI Tunda Kompetisi Putaran Kedua”, www.detiksport.com, 27 Juli 2011, 17:08 WIB). Namun sekitar tujuh jam kemudian, pihak LPI meralat keterangan tersebut. Ralat disampaikan oleh juru bicara LPI Abi Hasantoso yang menerangkan bahwa pengumuman tersebut merupakan data yang salah dan putaran kedua tetap digelar 17 September ("LPI Bantah Penundaan Putaran Kedua", www.detiksport.com, 28 Juli 2011, o0:11 WIB). Dari pengamatan yang dilakukan penulis saat itu, LPI kemudian menghapus pengumuman mengenai penundaan di situs resminya. Sementara itu di situs resmi LPI juga tidak dicantumkan pernyataan mengenai adanya ralat.
Apa yang dilakukan oleh LPI menunjukkan mereka tidak konsisten, tidak terbuka, dan tidak segera menanggapi rumor yang ada. LPI terkesan "membiarkan" rumor-rumor yang mengatakan bahwa kompetisi sudah tidak berlangsung lagi beredar secara meluas. Jika mengacu pada prinsip bahwa organisasi memiliki waktu maksimal 12 jam untuk memberikan respon awal, maka yang dilakukan LPI sudah sangat parah karena hampir satu bulan mereka membiarkan kabar burung beredar tanpa berusaha untuk memberikan klarifikasi.

LPI juga bertindak tidak konsisten, karena merilis pernyataan kemudian melakukan ralat. Bahkan pernyataan juru bicara LPI Abi Hasantoso - dengan menyatakan pengumuman tersebut merupakan data yang salah menunjukkan kinerja tim manajemen krisis di LPI tidak bagus. Tidak ada koordinasi antara fungsi dalam organisasi dalam memberikan keterangan. Selain itu mereka tidak satu suara. Hal tersebut juga menunjukkan bahwa pihak LPI tidak menyiarkan fakta secara proaktif, memberikan jawaban atau tanggapan secara terbuka dengan informasi yang faktual, dan berkomunikasi secara terus menerus.

\section{Penutup}

Keberadaan internet dan media sosial memang telah mengubah praktik PR. Dalam komunikasi krisis, PR sebuah 
perusahaan atau organisasi kini tidak hanya menjawab pertanyaan media massa saja, tetapi juga menjawab pertanyaan publik. Media sosial seperti Facebook dan Twitter memungkinkan untuk mencapai publik secara langsung. Hal ini apabila dimanfaatkan secara maksimal dapat memberikan dampak positif bagi perusahaan atau organisasi yang terkena krisis. Pasalnya organisasi atau perusahaan tersebut dapat menyampaikan pesan menurut versi mereka sendiri. Sebelum ada situs resmi dan media sosial, perusahaan atau organisasi hanya bisa menjawab melalui media. Tentunya tidak ada jaminan pernyataan yang disampaikan akan sama dengan yang dipublikasikan di media.

Media sosial menjanjikan konsekuensi positif bagi profesi PR, asalkan praktisi PR mampu memaksimalkan potensi media sosial. Konsekuensi positifnya adalah praktik PR akan menjadi lebih global, lebih strategis, komunikasi yang terjalin dua arah dan interaktif, serta bertanggungjawab secara sosial. Meski cukup banyak manfaat ketika menggunakan media sosial sebagai bagian dari praktik PR, namun ternyata perkembangan penggunaan teknologi komunikasi dalam praktik PR cukup lambat. Penelitian Gillin (2008) menunjukkan lebih dari separuh responden (59 \%) menilai bahwa teknologi tersebut belum digunakan secara maksimal. Sementara Mc Lennan \& Howell (2011) menilai kondisi itu bisa dibilang merupakan hal yang wajar. Pasalnya teknologi informasi, termasuk media sosial, menambah level kompleksitas akibat adanya perubahan lingkungan komunikasi di mana praktisi PR beroperasi.

Agar pemanfaatan media sosial oleh organisasi atau perusahaan - baik itu dalam komunikasi krisis mau pun kegiatan komunikasi yang lainnya - bisa optimal, maka diperlukan perubahan pola pikir dari PR itu sendiri. PR harus ingat bahwa media sosial, Media sosial, dengan berbagai karakteristiknya, menuntut PR untuk menyesuaikan diri. Hadirnya media sosial menjadikan komunikasi bersifat dua arah, meruntuhkan paradigma kontrol pesan, dan menciptakan bentuk baru dalam memonitor dan menganalisis media (Grunig, 2009; Macnamara, 2010). Artinya PR tidak bisa lagi hal-hal seperti memposting informasi yang tidak konsisten, menghapus konten di situs resmi atau di media sosial mereka, serta tidak segera berkomunikasi atau memberikan keterangan awal ketika tersebar rumor atau kabar burung yang mengancam perusahaan.

Artinya praktisi PR organisasi atau perusahaan harus memasukkan atau melibatkan media sosial dalam perencanaan penanganan krisis yang mereka miliki. Dalam penelitiannya, Wigley dan Zhang (2011) menemukan bahwa hampir separuh (48 \%) praktisi PR yang menjadi responden menyatakan menggunakan media sosial sebagai bagian 
dari persiapan menghadapi krisis organisasi. Media sosial digunakan untuk distribusi informasi, isu manajemen, pemantauan terhadap potensi krisis, serta mendeteksi persepsi-persepsi publik yang keliru mengenai organisasi.

Tentu hal terakhir yang harus diingat, komunikasi krisis bukan hanya pekerjaan departemen PR semata. Komunikasi krisis, sebagai bagian dari manajemen krisis, tentu melibatkan fungsi-fungsi lain dalam organisasi. Komunikasi krisis di era media sosial menuntut kerja sama yang lebih baik antara departemen PR dengan fungsifungsi lain dalam organisasi untuk bisa menyediakan informasi dengan segera, dan informasi tersebut akan terus konsisten. Melalui media sosial, PR juga bisa terus memantau isu-isu yang terjadi di dunia media sosial, sebelum kemudian melaporkannya sebagai bahan pertimbangan keputusan bagi manajemen.

\section{Daftar Pustaka}

Ardianto, Elvinaro. Lukiati Kumala \& Siti Karlinah. 2007. Komunikasi Massa Suatu Pengantar, Edisi Revisi. Bandung: Simbiosa Rekatama Media.

Argenti, Paul A. 2009. Corporate Communication, Fifth Edition. New York: McGraw Hill
Cornelissen, Joep. 2011. Corporate Communication A Guide to Theory and Practice, 3rd Edition. London: Sage.

Coombs, Timothy W. 2006. "Crisis Management: A Communicative Approach”. Public Relations Theory II. Carl H. Botan \& Vincent Hazelton (eds.). Mahwah: Lawrence Erlbraum Associates.

Cutlip, Scott M. Allen H. Center \& Glen M. Broom. 2005. Effective Public Relations Merancang dan Melaksanakan Kegiatan Kehumasan dengan Sukses, Edisi 8 (Chendra Leva, Terj.). Jakarta: Indeks.

Ferguson, Sherry Deveraux. 1999. Communication Planning an Integrated Approach. Thousand Oaks: Sage.

Hardjana, Andre A. 1998. "Manajemen Komunikasi dalam Krisis". Jurnal Ikatan Sarjana Komunikasi Indonesia Vol II/Oktober. Bandung: Remaja Rosdakarya, hal. 12-24.

Haryanto, Ignatius. 2011. "Jurnalisme dan Media Sosial”. Harian Kompas, 24 September 2011.

Gillin, Paul. 2008. "New Media, New Influencers and Implications for the Public Relations Profession" . Journal of New Communications Research Vol II Issue 2, Society for New Communciations Research and 
Institute

for

$P R$.

http://cdn.blogosfere.it/iab/images/

NewInfluencer.pdf, diakses 19

November 2011.

Grunig, James. 2009. "Paradigms of Global Public Relations in an Age of Digitalisation”. Prism Journal 6(2). http://www.prismjournal.org/filead min/Praxis/Files/globalPR/

GRUNIG.pdf, diakses 19 November 2011.

Holmes, Whitney. 2011. Crisis Communications and Social Media: Advantages, Disadvantages and Best Practices. http://trace.tennessee.edu/cgi/view content.cgi ?article $=1003 \&$ context $=c$ cisymposium\&sei-

redir $=1 \&$ referer $=\mathrm{http} \% 3 \mathrm{~A} \% 2 \mathrm{~F} \% 2 \mathrm{Fw}$ ww.google.co.id\%2Furl\%3Fsa\%3Dt \%26source\%3Dweb\%26cd\%3D23\%2 6ved\%3DoCCcQFjACOBQ\%26url\%3 Dhttp\%253A\%252F\%252Ftrace.tenn essee.edu\%252Fcgi\%252Fviewconte nt.cgi\%253Farticle\%253D1003\%252 6context\%253Dccisymposium\%26rc t\%3Dj\%26q\%3Dnew\%252omedia\%2 520crisis\%2520communication\%26 ei\%3DoRqVTpCUK4murAf8rcmmB g\%26usg\%3DAFQjCNHtmq9tHxTo UsDbUGVoPhYywP6fAw\%26cad\%3 Drja\#search=\%22new\%2omedia\%2 ocrisis\%20communication\%22, diakses 21 November 2011.
Kyhn, Helene Stavem. 2008. Situational Crisis Communication Theory: Its Use in A Complex Crisis with Scandinavian Airlines' Grounding of Dash 8-Q4Oo Airlines. Master Thesis. Aarhus School of Business. http://pure.au.dk/portal-asbstudent/files/390o/Helene_Stavem _Kyhn-_Master_Thesis.pdf, diakses 19 November 2011.

Landau, Daniel A. 2011. How Social Media is Changing Crisis Communication: A Historical Analysis. Thesis. Fairleigh Dickinson University Madison.

http://www.danlandau.net/writing/ sources/research/danlandau_thesis. pdf, diakses 19 November 2011.

Macnamara, Jim. 2010. "Public Communication Practices in The Web 2.0-3.o Mediascape: The Case for PRevolution". Prism Journal 7(3). http://www.prismjournal.org/ fileadmin/Social_media/Macnamar a.pdf, diakses 15 November 2011.

McLennan, Ashleigh \& Howell, Gwyneth V.J. 2011. "Social Networks and the Challenge for Public Relations". Asia Pacific Public Relations Journal Vol. 11 , hal.11-19. http://www.deakin.edu.au/artsed/apprj/articles/11-mclennanhowell.pdf, diakses 20 November 2011. 
Millar, Dan Pyle. \& Heath, Robert Lawrence (ed). 2004. Responding to crisis: a rhetorical approach to crisis communication. Mahwah, New Jersey: Lawrence Erlbaum Associates.

Putra, I Gusti Ngurah. 1999. Manajemen Hubungan Masyarakat. Yogyakarta: Universitas Atma Jaya Yogyakarta.

Soule, Allison R. 2010 Fighting The Social Media Wildfire: How Crisis Communication Must Adapt to Prevent from Fanning The Flames. Thesis. University of North Carolina at Chapel Hill. http://rightsideofright.com/wpcontent/uploads/ 2010/10/Soule_Thesis_UBGwebsite .pdf, diakses 15 November 2011.

Tan, Ee Ling J. 2006. Singapore Airlines: A Study in Exemplary Crisis Communication. Thesis. Wichata State University. http://soar.wichita.edu/dspace/bitst ream/handle/ 10057/339/to6o28.pdf?sequence $=3$, diakses 18 November 2011.
Taylor, Maureen. \& Perry, Danielle C. 2005. "Diffusion of Traditional and New Media Tactics in Crisis Communication". Public Relations Review 31, hal. 209-217. http://global.asc.upenn.edu/fileLibr ary/PDFs/taylordiffusion.pdf, diakses 15 November 2011.

Wigley, Shelley \& Zhang, Weiwu. 2011. "A Study of PR Practicioners' Use of Social Media in Crisis Planning" dalam Public Relations Journal Vol 5 No http://www.prsa.org/intelligence/pr journal/documents/2011wigleyzhan g.pdf, diakses 15 November 2011. 
Jurnal komunikasi, Volume 6, Nomor 1, Oktober 2011 